\title{
A ESTÉTICA PRIMEVA NA OBRA DE GIUSEPPE PENONE
}

\author{
Marina Andrade Câmara Dayrell \\ UFMG
}

\begin{abstract}
Resumo: Busca-se no presente artigo, por meio dos conceitos bejaminianos de estética e política - principalmente em seus desenvolvimentos em Jaques Rancière e Susan Buck-Morss -, aparatos teóricos capazes de problematizar os procedimentos escultóricos trabalhados por Giuseppe Penone em um amplo apanhado de suas obras. Partindo do contexto italiano em que surge a Arte Povera, grupo do qual Penone fazia parte no início de seu percurso artístico, ponderamos em que sentido o escultor italiano se identifica com as demais produções do grupo para apontarmos aquelas noções privilegiadas por seu trabalho. Delineando os conceitos norteadores de sua produção, verificamos a pertinência de voltar-nos à etimologia da palavra estética, explorada por Walter Benjamin e seus estudiosos, a fim de compreender as implicações políticas da obra de Penone.
\end{abstract}

Palavras-chave: Giuseppe Penone. Estética. Política.

\begin{abstract}
We search, in the present article, through Walter Benjamin's concepts of aesthetics and politics - especially in its developments by Jacques Rancière and Susan Buck-Morss theoretical apparatus capable of questioning the sculptorics procedures by Giuseppe Penone worked on a broad overview of his works . Starting from the Italian context where appears Arte Povera, group which Penone belongs early in his artistic career, we identify in which direction the italian sculptor identifies with other productions of the group to point out those notions privileged by his work. Outlining the guiding concepts of Penone's artistic production, we verified the appropriateness of returning to the etymology of the word aesthetics, explored by Walter Benjamin and his scholars, in order to understand the political implications of the Penone's work.
\end{abstract}

Key words: Giuseppe Penone. Aesthetics. Policy.

\section{Arte Povera italiana: do ambiente ao corpo}

Giuseppe Penone é um escultor italiano que fez parte do grupo da Arte Povera, movimento cujo nome foi cunhado pelo crítico Germano Celant e cujas primeiras manifestações ocorreram a partir da segunda metade da década de 60. Os artistas que compunham o grupo eram, em sua maior parte, italianos, mas também alemães, holandeses, gregos e britânicos, configurando um movimento internacional. O contexto italiano em que a Arte Povera se desenvolve é marcado por uma forte reação de artistas em relação ao tecnicismo que impelia o país em direção a uma recuperação rápida demais após o final da Segunda Guerra Mundial. Era o chamado miracolo italiano, em que cidades como Milão e Turim eram palco de uma exacerbada atividade industrial. Era precisamente frente a esta situação que se posicionava o 
movimento da Arte Povera, cuja tomada de posição abrangia outras disciplinas artísticas, para além das artes plásticas e visuais.

Somente durante a década de 60 foram produzidas pelo cinema italiano obras como Otto e Mezzo, 1963 e Satyricon, 1969, de Federico Fellini enquanto Pier Paolo Pasolini realizava não menos que Accattone, 1961; Mamma Roma, 1962; Comizi d'amore, 1964; Il Vangelo secondo Matteo, 1964; Edipo re, 1967; Teorema, 1968 e Medea, 1969. Nos atendo ainda na década de 60, Michelangelo Antonioni, por sua vez, tematiza o novo proletariado industrial em seu filme Il deserto rosso, 1964, sendo que esta mesma temática, conjugada àquela do extremo isolamento individual, estava presente também em sua trilogia L'avventura, 1960, La notte, 1961 e L'eclisse, 1962. Um dos exemplos mais emblemáticos sobre o posicionamento contra o estilo de vida que então se impunha talvez seja a sequência e seu filme Zabriskie Point, 1970, em que objetos, bens de consumo e fragmentos do cotidiano são lançados pelo ar por uma série de explosões durante vários minutos da parte final do filme como alusão ao desejo da geração jovem em destruir os excessos acumulados, na tentativa de divergir do modo de vida daquele mundo tal como ele se desenvolve no segundo Pós-Guerra.

A Arte Povera, buscando este contraste com o momento de exasperação industrial e tecnológica, focava a ideia de um conhecimento direto e não mediado em que natureza e cultura poderiam coincidir. Através do uso de materiais simples como carvão, madeira, eletricidade, enfim, materiais não nobres ou belos, a Arte Povera explorava leis e processos derivados do poder da imaginação e não baseadas em teorias científicas. Em 1970 o crítico suíço Jean-Cristophe Ammann definia a Arte Povera como um abandono da sociedade industrializada, por uma reinvindicação moral sobre "a sensibilidade subjetiva em sua autenticidade objetiva que reflete uma reminiscência natural do fenômeno ambiental”. (CHRISTOV-BAKARGIEV, 1999, p. 15). A Arte Povera reivindica esta tomada de distância de conceitos científicos, voltando seus procedimentos para uma atenção a qualidades do ambiente doméstico onde relações reais ocorrem. A temática do ambiente doméstico - do espaço enquanto habitação - perpassava especialmente a Arte Povera do contexto italiano, como fica evidente, por exemplo, nos inúmeros iglus realizados por Mario Merz. 

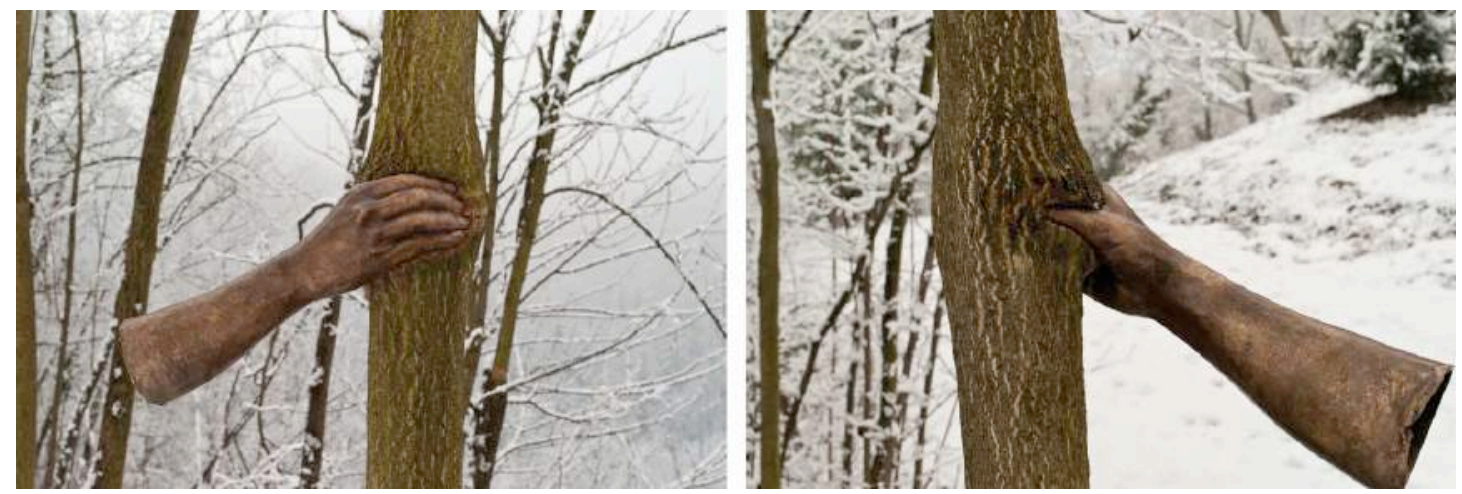

Uma das primeiras exposições do grupo, que acontece em 1966, na Sperone Gallery de Torino, recebe, de fato, o título de Arte abitabile.

Mario Merz realizava experimentações contínuas tanto com materiais provenientes da natureza quanto com objetos comuns, iluminados muitas vezes por formas em néon que evidenciavam a movimentação energética. Os néons são dispostos, em suas obras, na maioria das vezes, formando os números da série Fibonacci que indica as progressões que simbolizam a energia proliferante da realidade da natureza. De 1968 até o fim de sua vida artística, Merz reproduz a figura do iglu em diversos materiais como terra, pedras, fragmentos de vidro, feixes de lenha, metal e outros. Esta construção espacial e ambiental foi explorada e interrogada por Merz enquanto construção primária, análoga ao corpo.

A busca por uma nova forma estética e de reflexão baseada na experiência sensorial da energia, caracteriza um ponto comum dentre as propostas da Arte Povera. Ainda que se trate de um grupo com produções bastante heterogêneas percebe-se uma convergência dentre as suas proposições estéticas em direção àquilo que seria uma espécie de "sensível primeiro", não mediado, conforme já dito. Apontava-se para a necessidade de minimizar e simplificar a arte justamente para realizar aquilo que se chamou de "empobrecimento" da experiência no intuito de identificar as percepções através do fluxo de energia.

A exploração deste procedimento pode ser identificada também na obra Piccola torsione, 1968, de Giovanni Anselmo (Figura 2), em que o artista contorce, com o uso de um bastão de madeira, um pedaço de couro preso a um bloco de cimento. Após a torção, o bastão permanece então apoiado na parede da sala da exposição, evidenciando, assim, pela tensão, a energia da movimentação energética que se dá a ver ainda que em uma situação de aparente imobilidade. 


\section{Penone e a Arte Povera}

Os primeiros trabalhos de Giuseppe Penone foram realizados já dentro do grupo da Arte Povera, em um panorama de questionamento da fé acrítica na ciência e do progresso da modernidade. Ele compartilha com o grupo também a rejeição da estética das vanguardas que fizeram apologia à ideia da máquina, assim como a atenção voltada para o mito e para uma certa noção de origem.

Penone nasceu em Garessio, uma pequena vila de montanha da região do Piemonte, onde não havia escola especializada em artes, o que o leva a frequentar uma instituição focada em economia. Somente aos 19 anos, em 1966, ele se inscreve no curso de escultura da Academia Albertina de Belas Artes de Torino, que frequentou até 1970 .

Tendo produzido suas primeiras obras com idade entre 21 e 22 anos, ele afirma que não se filiava a nenhuma tradição e que não tinha a bagagem necessária para tal, mas que sabia poder trabalhar com o conhecimento de sua própria existência, com seu corpo e com sua vida.

Dentro do grupo da Arte Povera, no entanto, Penone afirma se identificar menos com artistas como Mario Merz ou Jannis Kounellis e mais com Gilberto Zorio ou Giovanni Anselmo com quem compartilha um conceito de arte que não parte de convenções estéticas, mas sim de reflexões que tem como objetivo não a pintura ou a escultura enquanto produtos, mas antes a reflexão a partir de uma observação sensória sobre a realidade.

Penone considera Merz, por exemplo, um artista tradicional em função do uso que ele fazia de estruturas, convenções e modelos existentes, como a forma do iglu e a própria série Fibonacci. Giovanni Anselmo, por sua vez, trabalhava precisamente com o questionamento das convenções, como é possível observar, por exemplo, em sua obra Sem título, 1969, em que a pedra, dependurada no alto de uma parede nos faz questionar seu peso ao mesmo tempo em que dá a ver a invisibilidade da gravidade. 


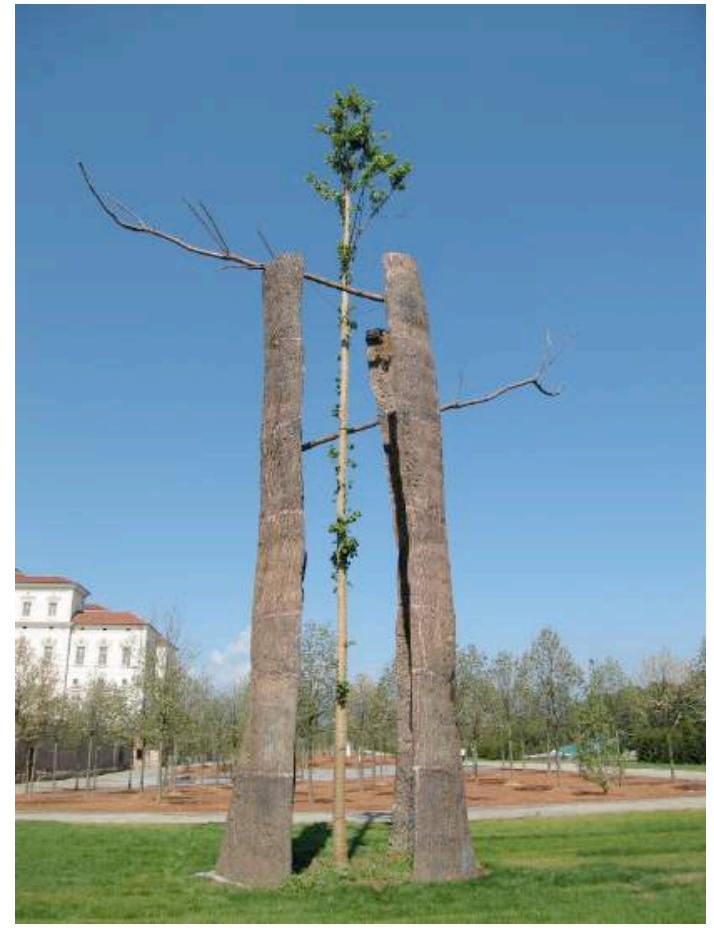

Os trabalhos de Penone são, em sua maioria, esculturas cujo tema mais recorrente é, sem dúvida, o da árvore. A maior parte delas é feita em bronze, ou através de intervenções diretas em árvores de bosques, como aquelas realizadas em sua primeira série intitulada Alpi Maritimi, de 1968.

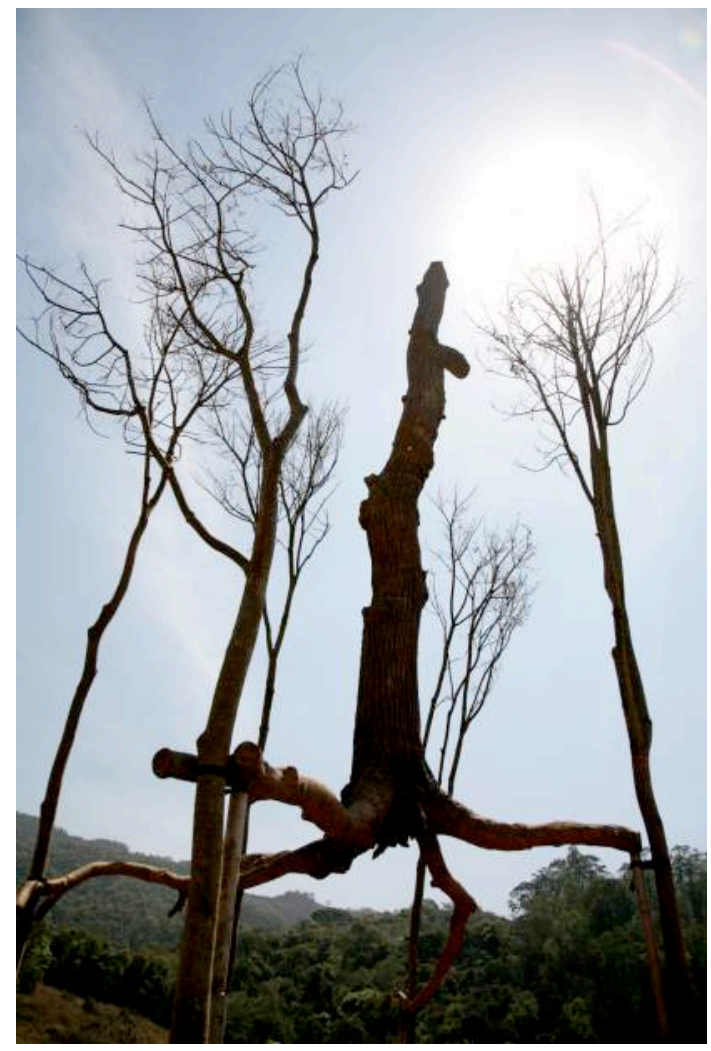


Já a partir desta série, fica evidente a noção de simbiose com a natureza, convocada por Penone, calcada na ideia de que o sensível é a nossa condição enquanto natureza e de que a experiência é algo que se dá na interseção entre o corpo e o espaço.

$\mathrm{O}$ artista retém que seus trabalhos exploram mais a realidade, em detrimento e para além das convenções de linguagem e dos sistemas de signos, e que seu interesse está nas especificidades da escultura e do material. A escolha do bronze por exemplo é, segundo ele, determinada pela associação que o material possui com culturas animistas, além, é claro, da sua capacidade de "moldar-se em torno dos corpos, reproduzindo-os perfeitamente." (SAMMLUNG GOETZ; SCHUMACHER, 2001, p. 159).

A questão das árvores em seu trabalho diz respeito, especialmente, à escultura e ao tempo. O artista trabalha com a noção de que para se observar as árvores precisamos de um tipo de percepção da realidade e de um conceito de tempo diferentes daqueles usados pela cultura ocidental. Relativizando a mensuração do tempo, ele passa a ver a árvore não como algo rígido, mas fluido. Para exemplificar esta relativização, ele realiza obras comparando o ato de comprimir argila com as mãos com o efeito obtido na obra Continuerà a crescere tranne che in quel punto, da série Alpi Marittime.

Trata-se portanto de uma percepção que privilegie seu estágio embrionário, ou seja, a sensibilidade, em detrimento de sua consequência, o cogito. É evocada uma noção do tempo capaz de nos fazer estabelecer uma experiência em que se possa compreender a própria consistência da matéria viva - a madeira - para além de sua rigidez.
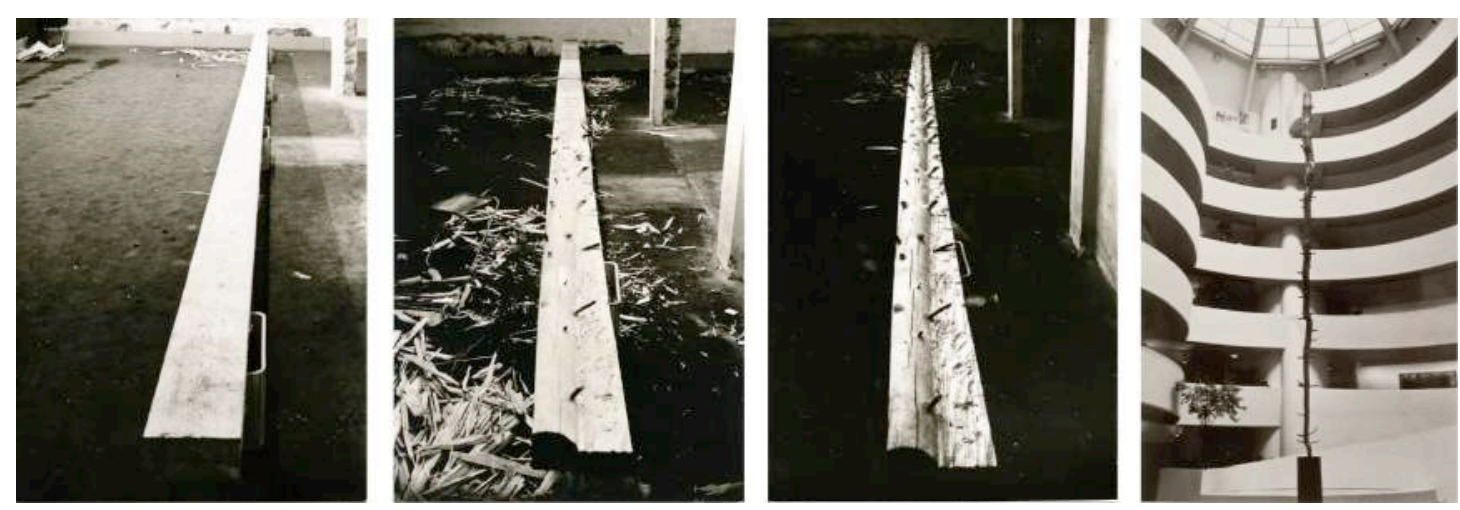


\section{A estética política da obra de Penone}

Em uma entrevista proferida em janeiro de 2013 à Radio italiana RAI 3 Penone declara, frente à indagação da entrevistadora sobre uma "certa ausência de questões de natureza política em suas obras":

[...] eu sustento que se faz-se um trabalho que, de algum modo, é aderente ao real, que leva em consideração aquilo que acontece e se produz consequentemente, de algum modo está implícito o valor político, está na obra. Uma obra, se é somente um enunciado de intenções ou de formas de protesto ou de denúncia, isso é muito importante, mas se arrisca muitas vezes de não haver uma força poética, de não haver uma força artística e, portanto, de ser muito limitada no tempo. Para haver uma possibilidade de sobrevivência no tempo uma obra deve ter um caráter de aderência à realidade [...] (PENONE, 2012).

Para compreendermos esta perspectiva de Penone, em que a aderência ao real implica, em si, um valor político, faz-se útil verificarmos algumas noções presentes nas teorias formuladas tanto por Susan Buck-Morss quanto por Jacques Rancière, a partir de seus estudos sobre as ideias de Walter Benjamin. Para Rancière a estética está intimamente vinculada com a realidade e, portanto, com a esfera tanto do político quanto da ética, enquanto, segundo Buck-Morss “[...] a estética contempla a esfera da arte como parte importante do sensível mas [...] o sensível [por sua vez] se estende à esfera do social e, portanto, do político"i (BUCK-MORSS apud ARCOS PALMA, 2009, p. 143). De acordo com estes pensamentos, o político não é a aplicação de uma ideologia através da arte, mas sim o contrário. A estética, por dizer originalmente sobre a experiência sensível em si, é uma condição inerente a todas as conformações políticas, já que o sensível não é "exclusividade nem privilégio de poucos, mas uma extensão da esfera humana e, portanto, de todos os setores sociais"ii (ARCOS PALMA, 2009, p. 146).

Logo, se a estética não é, claramente, algo de próprio do mundo da arte, mas antes, de tudo aquilo que perpassa as sociedades através do sensorium, ela é uma maneira de afrontar a existência e, portanto, de fazer política. Como vimos, é precisamente esta a característica que perpassa as pesquisas da Arte Povera, de um modo geral: uma maior atenção para as sensibilidades, ou seja, para as estesias. As experiências desenvolvidas por Penone em seu contato direto com a natureza seriam, 
portanto, um modo de intensificar esta busca estética, explorando a sinestesia ou a sensualidade implicada no corpo - nosso eu enquanto natureza - e as infinitas relações que partem do campo sensível.

Um outro viés importante para compreendermos como Penone trabalha a questão política em suas obras pode ser compreendido através do recorte oferecido por Rancière acerca de como a arte se articula com o real:

A arte não é política pelas mensagens e os sentimentos que transmite sobre a ordem do mundo. Não é política tampouco pela maneira pela qual representa as estruturas da sociedade, os conflitos e as identidades de grupos sociais. É política pela distância mesma que toma em relação à estas funções, pelo tipo de tempo e de espaço que institui, pela maneira mediante a qual corta este tempo e povoa este espaço.” (RACIÈRE apud ARCOS PALMA, 2009, p. 145).iii

Seria possível, portanto, pensar que o modo como Penone esculpe se aproxima dessa ideia corte temporal, sobre a qual fala Rancière. O distanciamento que o artista toma em relação à regente representação linear do tempo lhe permite desenvolver sua produção a partir do vínculo direto entre o sensível e o mundo e, consequentemente, explorar a característica temporal mais fundamental, qual seja, a multiplicidade.

Desta forma ele trabalha com a experiência do crescimento das árvores ao longo dos anos ao mesmo tempo em que realiza algo que se aproxima de uma arqueologia escultórica das árvores. A questão da percepção dos "micromovimentos", do fluxo energético contido no crescimento vegetal está presente em grande parte dos trabalhos de Penone, como aqueles da série de Alpi Marittime, mas também em obras como Tra scorza e scorza, 2003, ou Elevazione, 2011 (Fotos 9 e 10). São produções invisíveis ao presente. Elas, de fato, não existem no momento em que o artista faz a obra, mas se realizarão com o passar de dezenas de anos. Ao passo que obras como Albero di dodici metri, 1970, ou Cedro di Versailles, 2000-2003, são trabalhos em que o artista volta-se à estrutura da madeira como uma forma de enxergar, de maneira mais nítida, o passado da árvore, descobrindo o arbusto que veio a formar a trave ou a árvore adulta (Fotos 11 e 12). Penone despe e libera a madeira do seu próprio material a partir dos anéis de crescimento sucessivos àquele que é então revelado, redescobrindo dentro daquele corpo, sua juventude, por assim dizer, com seus ramos, seus incidentes, seu tempo vivido e sua forma. 
As árvores são, segundo o próprio artista, não um simples material, mas uma forma de vida em sintonia com nossa existência: "O que eu vi quando eu comecei foi que a distinção entre homem e natureza é falsa. O homem é parte da natureza; é o nosso desejo de conservar distinções que nos manteve separados”iv (PENONE, 2012) - o que levantaria ainda toda uma discussão ontológica sobre o que levou o homem a distinguir-se e formar-se enquanto homem.

Atendo-nos propriamente à questão da percepção sensível do tempo, Penone afirma, não só que a árvore é a forma mais extraordinária de escultura existente, mas também que ela é uma escultora em si que memoriza todos os gestos da sua vida em sua estrutura, sendo assim "uma forma que busca o equilíbrio no espaço" (PENONE, 2012). Ele enxerga na árvore o seu poder de matéria auto-plasmável, que pode não somente englobar os corpos com os quais ela entra em contato, mas que se plasma no interior do bosque quando, por exemplo, em zonas de sombra, suas hastes se alongam em busca da luz. Estes aspectos o levaram a refletir sobre a árvore como uma matériaescultura vivente, com grande força emblemática em relação à ideia da escultura.

O crítico Jean Christophe Ammann, escrevendo em 1977 sobre o trabalho de Penone, diz que: “[...] as obras que abordam a ideia de crescimento são apresentadas como uma cadeia de efeitos que acontecem dentro até mesmo da menor das transformações"v (AMMANN apud CHRISTOV-BAKARGIEV, 1999, p. 267). A fim de explorar as observações de Penone sobre os micro-movimentos energéticos contidos, como especifica Ammann, nas menores escalas de transformações, Patrícia Franca-Huchet aproxima o trabalho de Penone às Notas sobre o Infra-mince criadas por Marcel Duchamp.

Infra-mince, seria o atributo ou adjetivo constituído por Marcel Duchamp para proposições estéticas, jogos semânticos, jogos com a linguagem [...]. É [...] o momento imponderável onde qualquer coisa que é selada, microscópica ou infinitesimal acontece. [É quando o] jogo da tactilidade e da sensualidade [...] se torna aparente com toda sua evidência. [...] O que Duchamp quer dizer através destas Notas está sempre relacionado com pequenas percepções, ou sentimentos muito fortes aí implicados (FRANCAHUCHET, 1998, p. 20-21).

As implicações sensuais evocadas pelo Infra-mince remetem às percepções sensíveis exploradas por Penone ao enfatizar momentos em que algo de infinitesimal parece não ser percebido: a relativização das qualidades das matérias e sobretudo a 
convicção de que tais experiências e percepções infinitesimais são possíveis somente pela nossa irrevogável condição enquanto natureza, que é o nosso corpo entregue ao "jogo de tactilidade e sensualidade".

Se Penone afirmou que, quando ainda jovem "sabia poder trabalhar com o conhecimento de sua própria existência, com seu corpo e com sua vida", ele de fato não hesita "em convocar todos os acentos teóricos que estão ligados aos conceitos de um Merleau-Ponty [...]” (FRANCA, 1998, p.102). A produção de Penone parece evocar por exemplo o pensamento merleaupontyano presente em afirmações feitas precisamente no capítulo intitulado "A "Sensação" de seu livro Fenomenologia da percepção: “[...] o próprio do percebido é admitir a ambiguidade, o 'mutável ' é deixar-se modelar por seu contexto" (MERLEAU-PONTY, 1971, p. 29). Efetivamente não é outro o fio condutor das esculturas de tempo feitas por Penone, já que todas elas se localizam sensivelmente em uma zona entre o homem e as árvores, admitindo sempre a multiplicidade da natureza como única (não)ordem, e considerando, sobretudo, que "[...] é este domínio pré-objetivo que temos que explorar em nós mesmos se queremos compreender o sentir" (MERLEAU-PONTY, 1971, p. 30)

Pensando, por exemplo, na obra Rovesciare i propri occhi, 1970, temos que Penone, ao usar lentes espelhadas, se abstém da percepção visual do seu entorno, imergindo na experimentação das demais qualidades sensoriais (Figura 13). "Fechamos os olhos para ver", diria James Joyce (JOYCE apud DIDI-HUBERMAN, 1998, p. 30). É da multiplicidade de sentidos do corpo, para além da visão, que esta obra trata:

\footnotetext{
Quando os olhos estão abertos, é o nosso olhar sobre "até onde nossos olhos podem enxergar" que revela nossa extensão física. [...] O espaço que vemos se reflete na nossa mente transformando-se na extensão do nosso corpo. Fechando os olhos define-se o corpo pelo volume que ele possui efetivamente. (PENONE, 2009).
}

Didi-Huberman, ao se questionar sobre o que significa a afirmação de Joyce, conclui que "ver só se pensa e só se experimenta em última instância numa experiência do tocar" (DIDI-HUBERMAN, 1998, p. 31). A operação de Penone, nesta obra, é aquela de limitar as aberturas perceptivas - os olhos - para abrir ainda mais as demais possibilidades sensíveis e nelas imergir. E se Penone afirma que o 
espaço é a propagação do olhar, cegando-se, o que ele percebe é seu próprio espaço corporal.

\section{A re-inversão do sistema sinestético}

Susan Buck-Morss, em seu artigo chamado "Estética e Anestética: O 'Ensaio sobre a obra de arte' de Walter Benjamin reconsiderado", recorre ao sentido etimológico original da palavra "estética" que em grego quer dizer perceptivo através do tato. O campo original da estética seria, como vimos, não a arte, mas a realidade enquanto natureza corpórea e material. Dizendo de outro modo: "A estética nasceu como um discurso do corpo" (EAGLETON apud BUCK-MORSS, 1996, p. 13).

Buck-Morss, em suas considerações sobre o texto benjaminiano, indica que o sistema nervoso não se limita ao corpo e que o circuito que vai da percepção sensorial à resposta motora tem tanto seu início quanto seu fim no mundo, ou seja, o circuito perceptivo começa e acaba no espaço. Deste modo o cérebro é entendido como parte de um sistema que passa através da pessoa e de seu ambiente em contraposição ao que retém a concepção tradicional do sistema nervoso humano que isola a biologia humana de seu ambiente.

A filósofa pontua, entretanto, que na era moderna, o termo estética sofre uma inversão e passa a ser aplicado antes à arte - a formas culturais, em detrimento de sua acepção original de experiência sensível. A noção de refinamento do gosto diria respeito, portanto, precisamente, a uma espécie de "treinamento dos sentidos", ou talvez pudéssemos dizer: a sua inibição parcial.

Ao afirmar que o campo do circuito sensorial é a experiência que realiza, por sua vez, a mediação entre sujeito e objeto e que esta é tornada, de certo modo, irrelevante pela inversão do sentido da estética na modernidade, a filósofa, seguindo o pensamento benjaminiano, mostra como a alienação sensorial se encontraria na origem da estetização da política e como, portanto, esta alienação sensorial e a estetização da política caracterizaram as condições sensuais da modernidade.

Para Walter Benjamin a experiência moderna é neurológica, centrada no choque, baseada, por sua vez, na noção freudiana de que a consciência seria um escudo que protege o organismo contra estímulos, ou seja: "quanto mais prontamente a consciência registra esses choques, tanto menos provavelmente eles terão um efeito traumático" (BENJAMIN apud BUCK-MORSS, 1996, p. 22). Se, entretanto, o interesse de Freud eram os choques aos quais soldados da Primeira Guerra tinham 
sido submetidos, a experiência do campo de guerra era compreendida por Benjamin como a norma da vida moderna. E se dá então a chamada inversão dialética, ou seja, a estética tenderia então a abandonar seu papel de modo cognitivo de contato com a realidade, transformando-se em uma maneira de barrá-lo, configurando, assim, a destruição do poder do organismo de responder politicamente.

\begin{abstract}
A percepção torna-se experiência apenas quando se conecta com memórias sensoriais do passado; mas o "olho defensivo" que rechaça as impressões, "não se entrega a devaneios acerca das coisas remotas". Ser defraudado da experiência tornou-se o estado geral, sendo o sistema sinestético dirigido a esquivar-se aos estímulos tecnológicos, de maneira a proteger tanto o corpo do trauma de acidentes como a psique do trauma do choque perceptual. Como resultado, o sistema inverte seu papel. O seu objetivo é o de entorpecer o organismo, insensibilizar os sentidos, reprimir a memória: o sistema cognitivo da sinestética tornou-se, antes um sistema de anestética. (BUCK-MORSS, 1996, p. 23-24)
\end{abstract}

Na chamada "crise da percepção" o nosso sistema sensorial, que originalmente era nosso meio de contato com o espaço sofre, então, uma espécie de inversão funcional. Segundo Benjamin, a partir das experiências modernas com as máquinas, questionadas, como vimos, posteriormente, pelos artistas da Arte Povera, nosso sensorium passa a nos anestesiar diante dos estímulos do espaço.

Não é outra a pesquisa desenvolvida por parte do contexto artístico italiano do segundo Pós Guerra. São posicionamentos frente às consequências do então chamado miracolo italiano e seu tecnicismo. E é na natureza que Penone encontra os estímulos capazes de ampliar as possibilidades perceptivas de seu corpo, ou seja, de sua condição natural. As percepções "infra-finas” observadas tanto em si quanto no crescimento e plasmabilidade das árvores indicam que não há perda de experiência, senão uma experiência anestesiada cujas consequências estariam precisamente na necessidade sempre maior da mediação das máquinas em detrimento da tactilidade e mediação sensível com o mundo que revela, por sua vez, possibilidades múltiplas para além dos mecanicismos maniqueístas.

Esta recuperação da capacidade sensível põe luz sobre o fato de o contato com mundo mediado por máquinas indicar somente o tempo linear como única forma de experiência possível. Ao recuperar, escultoricamente os modos como os tempos estão 
imbricados, Penone indica formas outras de experienciarmos o tempo, nos dando a ver sua invisibilidade e nos mostrando o passado lampejando no presente.

Se para Penone a estética é não só um discurso do corpo, mas também e, sobretudo, um discurso que nasce da relação entre corpo e ambiente, sua produção se coloca de modo tão político quanto urgente. A política se torna um desdobramento natural da estética suas obras, a partir daquilo que norteia sua produção desde as primeiras obras: que o sensível é a condição do homem enquanto natureza, e que dela somos um simples desdobramento.

\section{REFERÊNCIAS}

ANSELMO, Giovanni. Piccola torsione / Giovanni Anselmo. 1968. Disponível em: < http://gammm.org/index.php/2010/07/22/piccola-torsione/>. Acesso em: 14 maio 2012.

- Untitled (Giovanni Anselmo) 1969. Disponível em: $<$ http://www.essogallery.com/ARTE\%20POVERA/Images\%20Photo/007.html . Acesso em: 14 maio 2012.

ARCOS PALMA, Ricardo Javier. La estética y su dimensión política según Jacques Rancière. Nómadas, Bogotá, n. 31, oct. 2009. Disponível em: $<$ http://www.scielo.org.co/scielo.php?script=sci_arttext\&pid=S0121$75502009000200010 \& \operatorname{lng}=$ es\&nrm=iso $>$. Acesso em 31 out. 2012.

BENJAMIN, Walter; ROUANET, Sergio Paulo; GAGNEBIN, Jeanne-Marie. Magia e técnica, arte e política: ensaios sobre a literatura e história da cultura. 7. ed. São Paulo: Brasiliense, 1994. 253p.

BUCK-MORSS, Susan. Estética e Anestética: O "Ensaio Sobre a Obra de Arte de Walter Benjamin reconsiderado. In: Travessia - revista de Literatura - n.33. UFSC Ilha de Santa Catarina, ago-dez; p. 11-41, 1996.

CHRISTOV-BAKARGIEV, Carolyn. Arte Povera. London: Phaidon Press Limited, 1999. $304 \mathrm{p}$. 
DIDI-HUBERMAN, Georges. O que vemos, o que nos olha. São Paulo: Ed. 34, $1998.260 \mathrm{p}$.

FLOOD, RICHARD; MORRIS, FRANCES; WALKER ART CENTER; TATE MODERN (GALLERY). Zero to infinity: arte povera, 1962-1972. 1st ed. Minneapolis, Minn.: Walker Art Center; New York: Available through D.A.P./Distributed Art Pub., c2001. 367 p.

FRANCA-HUCHET, L'infra-mince, Zona de Sombra e o tempo do entre-dois. Porto Arte, Porto Alegre, v. 9, n. 16, 19-26, maio, 1998. Disponível em: <http://seer.ufrgs.br/PortoArte/article/view/27748>. Acesso em: 31 out 2012.

MERLEAU-PONTY, Maurice. Fenomenologia da percepção. Rio de Janeiro: Ed. Freitas Bastos, 1971. 465 p.

MERZ, Mario. Untitled, 1998. Gladstone Gallery, Selected works. Dsiponível em: < http://gladstonegallery.com/artist/mario-merz/work\#\&panel1-1>. Acesso em: 01 maio 2012.

PENONE, Giuseppe. Giuseppe Penone Documentary. Ikon Gallery, 2009. Disponível em: $\quad<\quad$ http://www.ikongallery.co.uk/programme/current/gallery/299/giuseppe_penone/> . Acesso em: 2 jun 2011.

- GIUSEPPE PENONE per Radio3, 2012. Disponível em: $<$ http://www.radio3.rai.it/d1/radio3/programmi/PublishingBlock-b4e0f9e4-67894284-83ef-5bcb4c0b0bcf.html?refresh_ce>. Acesso em: 10 maio 2012.

- The root and the branch effect. Giuseppe Penone, a key figure in 'Arte Povera', is now creating a new work for the Whitechapel Gallery, 2012. Disponível em: $\quad<\quad$ http://www.ft.com/cms/s/2/f68b0488-eb81-11e1-935600144feab49a.html\#axzz2UUggfYWW>. Acesso em: 05 maio 2012. 
SAMMLUNG GOETZ; SCHUMACHER, Rainald. Arte povera from the Goetz

Collection. Rev. English ed. München: Sammlung Goetz, c2001. 272 p.

\footnotetext{
${ }^{i}$ Tradução nossa de "[...] la estética contempla la esfera del arte como parte importante de lo sensible sino también en que lo sensible se extiende a la esfera de lo social y, por ende, de lo político."

ii Tradução nossa de "[...] exclusividad ni privilegio de unos pocos sino una extensión de la esfera humana y por ende de todos los sectores sociales."

iii Tradução nossa de "El arte no es político antes que los mensajes y los sentimientos que transmite sobre el orden del mundo. No es político tampoco por la manera por

la cual representa las estructuras de la sociedad, los conflictos o las identidades de grupos sociales. Es político por la distancia misma que toma en relación con esas funciones, por el tipo de tiempo y de espacio que instituye, por la manera mediante la cual corta este tiempo y puebla ese espacio."

iv Tradução nossa de "What I saw when I began was that the distinction between man and nature is false. Man is part of nature; it is our desire to conserve distinctions that has kept us separate."

${ }^{v}$ Tradução nossa de "[...] the works addressing the idea of growth are presented as a chain of effects within even the smallest of transformations."
} 